\title{
Análise da Relação entre a Criação DE VALOR E OS DiReCionadores De VALOR no Setor de Saúde no Brasil (2002-2003)
}

\author{
Diógenes Manoel Leiva Martin \\ Prof. Dr. (FGV-SP)éprofessor do mestrado edoutorado \\ da UniversidadePresbiteriana Mackenzie(UPM) \\ diomartin@mackenzie.com.br \\ André Wakamatsu \\ Prof. MSc (PO LI-USP)éprofessor da graduação \\ da UniversidadePresbiteriana Mackenzie(UPM) \\ wakamatsu@mackenzie.com.br
}

Edson 0 liveira

Prof. MSc (Mackenzie), éexecutivo financeiro edson.oliveira@ge.com

Wilson Toshiro Nakamura

Prof. Dr. (FEA-USP) éprofessor do mestrado edoutorado da UniversidadePresbiteriana Mackenzie(UPM) wtnakamura@mackenzie.oom.br

\section{RESUMO}

Neste trabalho éanalisada, deforma empíica, a relação entre criação devalore os direcionadores devalor, financeiros enão financeiros, no setor de saúde no Brasil nos anos 2002 e 2003, sendo considerada uma amostra de 1070 empresas do setor. Como a grandemaioria das empresasé de capital fechado, 0 valor das empresas foi medido considerando indicadores financeiros de desempenho de margem e retorno. O sseguintes direcionadores devalor form estatisticamente significantes: 1) quantidade de equipamentos de alta tecnologia, 2) filiação ao SUS, 3) nível de endividamento, 4) valor do imobilizado e 5) idade das instituições de saúde. $\mathrm{Na}$ análise dos resultados verificou-seahipótese dequesomente aquantidade de equipamentos de alta tecnologiaé direcionador para a criação de valor, enquanto que as demais variáveis acarretam destruição devalor das empresas de saúde.

PALAVRAS - CHAVES: D irecionadores de Valor, Sistema Único de Saúde, Criação deValor.

\section{ABSTRACT}

In thispaper it isanalyzed empirically therelationship between valuecreation and thevalue-drivers, financial and no financial, of brazilian health-sector in theyears 2002 and 2003, with a sample of 1082 companies. Asthegreat majority of thecompaniesisnot public and itsvaluewas measured consideringfinancial margin and return indicators. Thefollowingvaluedriversweresignificant: 1) amount of equipments of high technology, 2) percentage of bedscharged to SUS, 3) filiation to SUS, 4) debt level, 5) value of theimmobilized and 6) amount of protests. In the analysis of theresultsthe hypothesiswasverified that only theamount of equipments of high technology isa relevant driver for valuecreation.

KEY WO RDS: Valuedrivers, SUS, ValueCreation, HighTech Equipments, Valuation. 


\section{INTRO DUÇÃO}

A saúde é um dos temas de discussão que apresenta maior repercussão no ambiente político e econômico brasileiro, em função de sua abrangência e relevância. D eacordo com aA ssociação Médica Brasileira, 137 milhões debrasileiros dependem do sistema público de saúde, o qual é atendido através do Sistema Único de Saúde (SUS). 0 Sistema de Serviços de Saúde é composto pelo Sistema Único de Saúde (SUS), 0 Sistema de A tenção Médica Supletiva e o Sistema de D esembolso Direto. O primeiro é um sistema público e os dois últimos são privados, estes divididos entre empresas com fins lucrativos enão lucrativos. Em 2004, o mercado de saúde no Brasil movimentou cerca de R $\$ 80$ bilhões. Em fev/ 04, 0 SUS contava com 6.106 hospitais em sua rede hospitalar, sendo 2.584 públicos e 3.522 privados, totalizando 434.752 leitos hospitalares. Não obstante estes números, a indústria só tem uma empresa de capital aberto. 0 Brasil ocupa a 125 posição em sistemas de saúde do mundo, considerando um universo de 191 países. Entretanto, em medicina privada, 0 Brasil é 0 segundo maior mercado, atrás apenas do Estados Unidos, segundo Estudo Setorial - LAFIS(2004).

O Brasil possui uma medicina bastante desenvolvida, com médicos de reconhecimento internacional que representam um excelente capital intelectual nesse setor. Nesse contexto, o segmento de saúde brasileiro, principalmente o privado, realiza inúmeros exames e tratamentos que exigem hospitais modernos, boas instalações e equipamentos de alta tecnologia. Esses equipamentos são, em sua maioria, importados de países como Alemanha, Estados Unidos, Japão, Holanda, entre outros. As aquisições desses equipamentos exigem altos investimentos em moeda estrangeira, incorrendo os compradores em uma série de tributos e em risco cambial.

Tendo em vista esse contexto, a utilização de equipamentos dealtatecnologia (direcionador de valor não financeiro) parece ter grande contribuição para a conquista, manutenção e melhoria da competitividade das empresas do setor de saúde brasileiro, tais como as clínicas, centros de diagnósticos por imagem, bem como os hospitais. Além disso, dado 0 alto custo para aquisição desses equipamentos, bem como 0 custo operacional elevado inerenteàs organizações de saúde, a utilização de dívidas (direcionador de valor financeiro) também parece ser de sumaimportância para que as organizações privadas de saúde possam se manter competitivas.

Esse estudo pode fornecer informações importantes para o estabelecimento de políticas de investimentos das empresas hospitalares, auxiliando seus gestores na tomada decisão, bem como pode reunir elementos que auxiliem aos legisladores em relação às políticas fiscais e tributárias para 0 setor. Além disso, pode ser de boa valia para bancos, fornecedores e instituições financeiras em geral na avaliação da viabilidade econômica de projetos de investimento na área de saúde, como forma de auxiliar na avaliação de risco e concessão de crédito para as organizações de saúde, pois pode fornecer a essas instituições informações tanto da influência da estrutura de capital como dos tipos de equipamentos existentes nas instituições que têm melhor e pior desempenho financeiro eque terão melhores ou piores condições de honrar seus pagamentos.

\section{O BJETIVO}

Este estudo tem como principal objetivo constatar empiricamentearelação entre criação devalor edirecionadores de valor, financeiros e não financeiros, para o setor de saúde no Brasil. Em função de somente uma empresa do setor de saúde ser de capital aberto, o valor das empresas será medido por indicadores financeiros de desempenho.

Não podeserignorado o fato de que este estudo éainda uma primeira tentativa de estudar drivers (direcionadores) de valor no contexto das empresas brasileiras, especialmenteno setor de saúde. Um conhecimento mais aprofundado acerca dos drivers de valor das empresas brasileiras poderá ter um significativo impacto sob a forma como os gestores analisam suas estratégias e tomam suas decisões no dia a dia.

\section{REFERENCIAL TEÓ RICO}

O referencial teórico é composto pela literatura sobre criação de valor e seus direcionadores, em especial a presença de equipamentos dealta tecnologia. Entretanto, com relação à natureza de cada direcionador de valor, haveránecessidade de se recorrer a outro conjunto de teorias oriundas da 0 rganização Industrial e Teoria dos Jogos.

\subsection{Valor}

A teoria da geração de valor para 0 acionista teve seu berço no fim dos anos 70 einício dos anos 80 com a aplicação do CAPM (Capital Asset Pricing Model) para o setor corporativo, ganhando proeminência em 1986 com a publicação do livro Creating Shareholder Value de Rappaport da Universidade de Northwestem (Rappaport, 1986). Ao entrar para o grupo Alcar, a abordagem de Rappaport (1986) introduziu o modelo de Fluxo de Caixa Livre, e mostrou como as técnicas de fluxo decaixa descontado poderiam seradaptadas e inseridas no modelo de valor para o acionista.

D e acordo com Black, Wright e D avies (2001) a publicação acima foi seguida por um livro menos conhecido, Managing for V alue de Bernard Reimann em 1987, que iniciou a ligação de criação de valor para o acionista com aarte de dirigir uma companhia, atraindo a atenção de consultorias.

$\mathrm{O}$ interesse na abordagem do valor do acionista recebeu mais atenção com a publicação do livro Valuation de Coppeland, Koller e Murrin (1990) que contém uma exposição detalhada das questões de criação de valor e como lidar com elas, mostrando que a aplicação dos princípios do valor 
do acionista para as empresas é possível, praticável e altamente desejável, levando a empresa a obter benefícios substanciais não apenas para os acionistas, mas também para outros stakeholders da empresa, tais como os clientes, os fornecedores, a sociedade e os empregados, entre outros.

No ano seguinte Stewart (1991) publicou TheQ uest for Valuequeaperfeiçoou aidéia deValor Econômico Adicionado ou Eoonomic ValueAdded-EVA ${ }^{\circledR}$, que segundo Black, Wright e D avies (2001) é como o "spread" entre o retomo sobre o capital e o custo de capital num dado período. Esse livro colocou mais atenção na medição detalhada do balanço patrimonial da empresa, e como certas contas necessitavam ser tratadas de forma diferente das utilizadas pelos contadores, tais como a depreciação, os ativos diferidos, entre outros ajustes.

De acordo com Helfert (2003), o valorpara o acionistaé criado quando os retornos de fluxo de caixa provenientes dos investimentos excedem o custo médio ponderado decapital da companhia. Isso representa o crescimento no valoreconômico do capital da empresa ao longo do tempo e tem como contrapartida os ganhos com dividendos e ganhos de capital. Deacordo com Rappaport (1998), Y oung e O 'Byme (2003) e Helfert (2003), a criação de valor para o acionista éa melhor expressão do sucesso corporativo.

Conforme podeser identificado na figura 1, a criação devalor para o acionista tem relacionamento com três tipos básicos dedecisões: as decisões de investimento, as decisões operacionais e as decisões de financiamento. Esses três tipos de decisões são apresentados do lado esquerdo da figura 1. A combinação das decisões de investimento edeoperação gera fluxos de caixa livres (após os impostos), enquanto as decisões definanciamento influenciam a estrutura de capital e 0 nível de custo médio de capital da organização. Aplicando-se o custo ponderado de capital como a taxa de desconto para 0 fluxo de caixa livre, determina-se o valor para 0 acionista. Ao mesmo tempo, o ciclo de vida do produto, a competição, a tecnologia e muitas outras influências afetam o tamanho ea volatilidade desses fluxos de caixa. Já o mercado de capitais influenciam a expectativa de retorno dos investidores e o custo médio ponderado de capital. Fonte: Adaptado de Helfert (2003)
Alternativamente, o lado direito da figura mostra que 0 valor para 0 acionista também pode ser baseado na combinação de dividendos pagos em dinheiro e realização de ganhos de capital, quando vistos pelos olhos do investidor. Esse ponto de vista do investidor é inseparável do fluxo de caixa livre que vai permitir o pagamento de dividendos pela companhia e também vai orientaro valor de mercado das ações, possibilitando ao investidor realizar os ganhos de capital. Também é possível criar valor minimizando dividendos e reinvestindo todos os fundos em oportunidades com valor presente líquido positivo.

O sistema VBM (Value Based Management) é um sistema de gestão cujo alicerceéa criação de valorpara o acionista. Segundo Peterson \& Peterson (1996) apud Basso etal (2004) para a escolha das medidas de desempenho a empresa deve considerar que: a) a medida escolhida não deve ser influenciada pelos métodos contábeis tradicionais; b) a medida deve levar em consideração os resultados futuros esperados; c) a medida deve considerar os riscos e d) a medida deve considerar os fatores que não estão no controle dos funcionários.

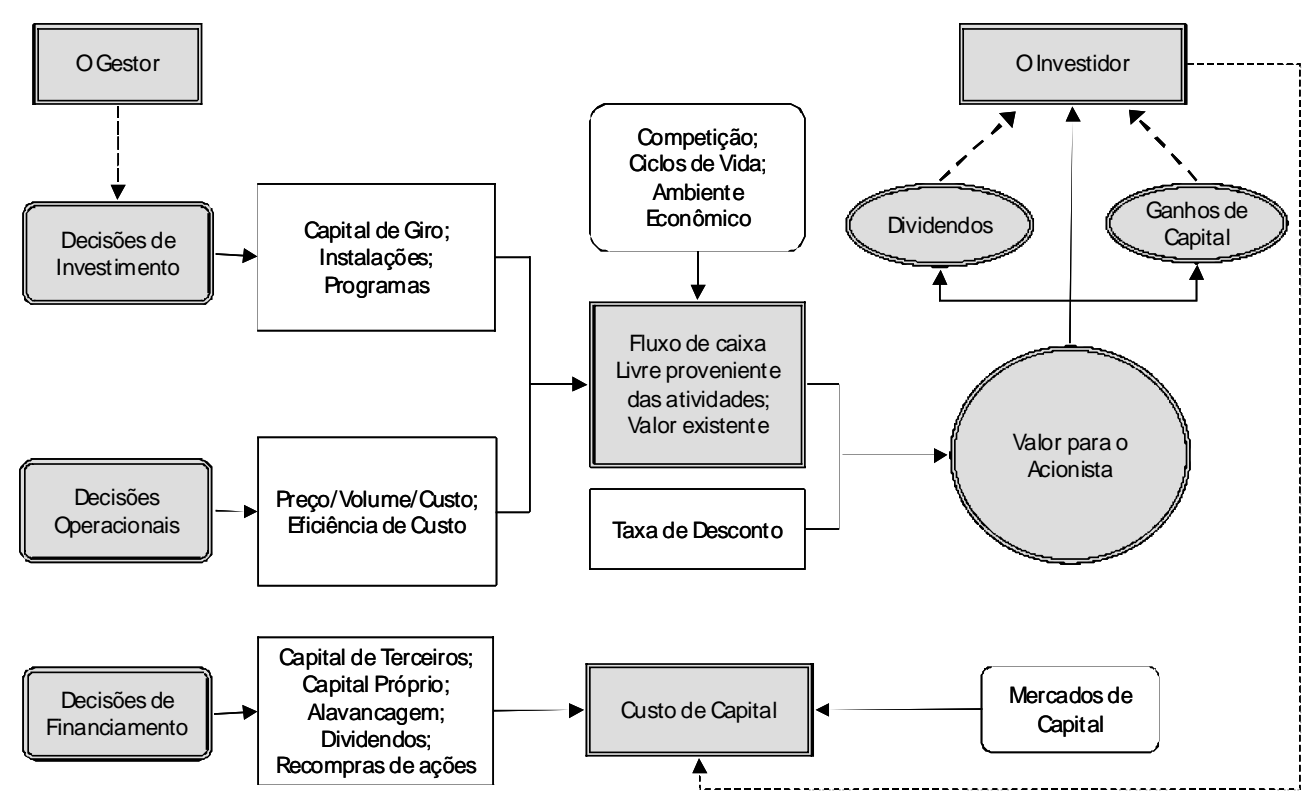

Expectativas

\section{Figura 1: A criação de valor para o acionista num contexto de Fluxo de Caixa}

\subsection{Direcionadores de Valor}

Rappaport (1998) define os direcionadores de valor como os parâmetros básicos para valoração. Copeland, Koller e Murrin (2000) os definem como as variáveis de desempenho sobre os quais a administração pode agir e que têm impacto nos resultados de um negócio, como por exemplo: a eficácia de produção ou a satisfação do cliente. As medidas 
associadas a esses direcionadores de valor são chamadas de indicadores chave de performance (ICP). São, portanto, os fatores que influenciam, direta ou indiretamente, na criação de valor deuma organização, e podem ser subdivididos em fatores financeiros enão financeiros. Drivers financeiros são basicamente medidas financeiras conhecidas e utilizadas pelos gestores e analistas financeiros, tendo porém como limitação não darem indicações sobre o potencial de geração de lucros futuros da empresa. Drivers não financeiros, ao contrário, justamente são medidas do desempenho operacional e estratégico da empresa e que indicam o potencial da empresa em gerar lucros consistentes ao longo do tempo.

Copeland, Koller e Murrin (2000) informam que os três princípios centrais para definir bem direcionadores devalor são: a) os direcionadores de valor devem ser diretamente relacionados à criação de valor para o acionista edisseminados em todos os níveis da organização; b) os direcionadores de valor devem ser definidos e medidos tanto por ICP's (indicadores chave de performance) financeiros, como por operacionais (os não financeiros) e c) os direcionadores de valor devem contemplar crescimento de longo prazo e também desempenho operacional.

Copeland, Koller e Murrin (2000) sugerem como uma consequêncianatural desses princípios, que cadaunidade denegócios devetere desenvolver sua própria listade direcionadores devalor eos ICP's - indicadores chave deperformance- equeo centro corporativo não deve cederàtentação deimporo mesmo modelo em todas as unidadesdenegócios deumaorganização. Mesmo que duas unidadesdenegóciosparticipem damesmaindústria, é importante que eles foquem em diferentes direcionadores de valorse seu desempenho for função de diferentes direcionadores. Como exemplo, uma unidade de negócios com desempenho operacionalemargens superiores deve se concentrar em direcionadores de valor e ICP's de crescimento, enquanto umaunidade denegóciosdebaixamargem deveria focar em direcionadores devaloreICP'srelacionadosaos custos.

Paraqueo valorpara 0 acionista possa ser constante e eficientemente otimizado, sefaz necessário que todos os níveis da organização tenham boanoção a respeito dos principais elementos quecon- tribuam paraisso. Para tanto éinteressante desenvolvera definição de direcionadores devalor que possam ajudar os gerentes em três aspectos, conformeapontam Copeland, Koller eMurrin (2000): a) auxiliar os gerentes de unidades de negócios e seus colaboradores aentender como o valor para o acionistaécriado e maximizado na empresa; b) amparar a priorização desses direcionadores devalore portanto determinar onde os recursos devem ser aplicados ou de onde devem ser removidos; c) alinhar os gerentes de unidades de negócios e empregados em relação aum entendimento comum das principais prioridades.

Rappaport (1998) identificou 7 direcionadores financeiros: a) crescimento das vendas; b) investimento em capital de giro; c) investimento em capital fixo (por exemplo, equipamentos de alta tecnologia); d) margem de lucro operacional; e) alíquota de imposto de renda; f) custo médio ponderado de capital eg) período de vantagem competitiva (quantidade de anos em que as taxas de retorno excedem o custo médio ponderado de capital).

Como pode ser visto na figura 2 os principais direcionadores de valor de Rappaport (1998) são fatores intermediários componentes das decisões gerenciais (representadas por operação, investimento e de financiamento), de forma a atingiracriação devalor (quesão os Fluxos decaixagerados pela operação, a taxa de desconto eaestrutura de capital representada pela porção de débito em relação a capital próprio). D e acordo com Rappaport (1986 e 1998), essas ligações são as molas propulsoras para a geração devalor para o acionista.

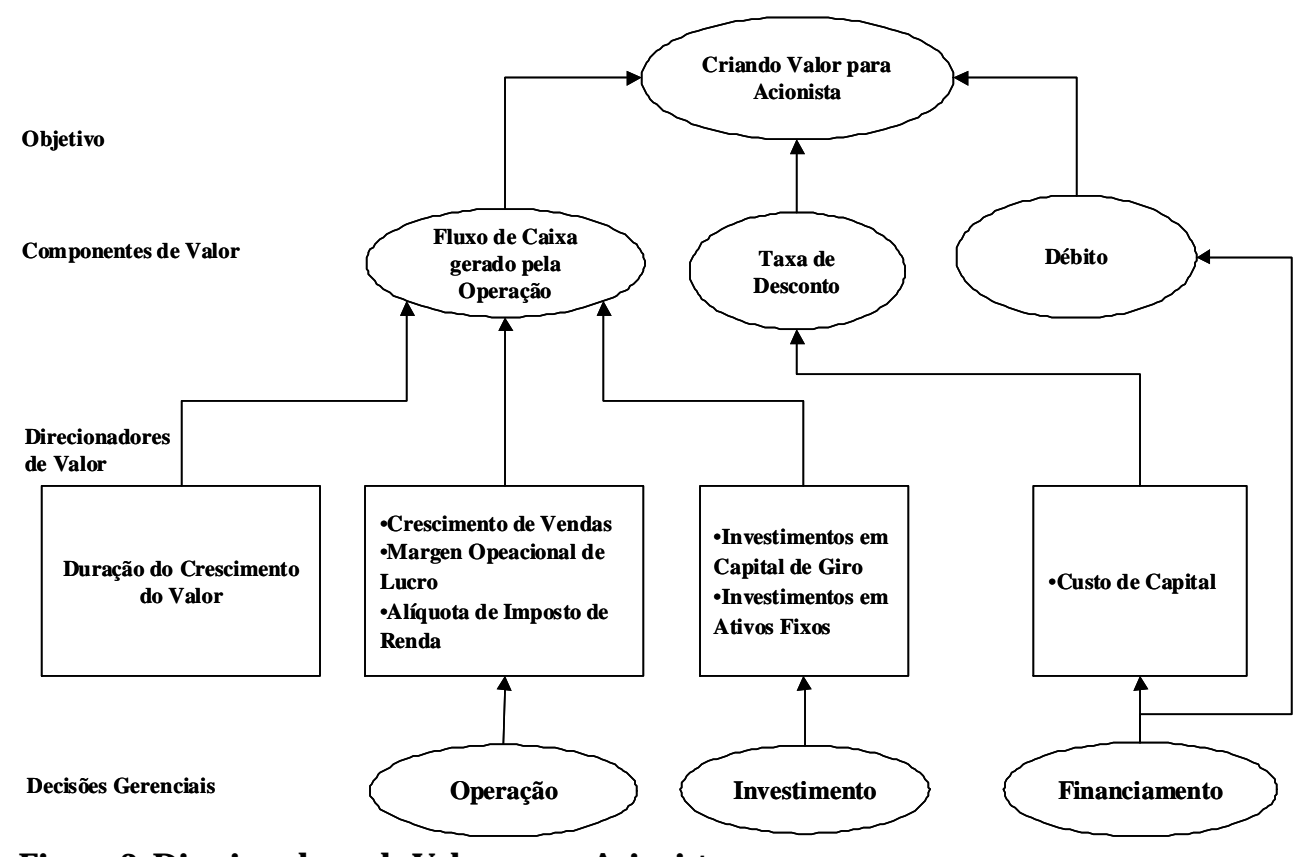

Figura 2: Direcionadores de Valor para o A cionista Fonte: Adaptado de Rappaport (1998)

Ittner et al (1997) sugerem os seguintes indicadores não financeiros: a) satisfação do cliente; b) objetivos estratégicos 
não financeiros; c) qualidade do produto ou serviço; d) segurança do empregado; e) produtividade; f) participação de mercado; g) satisfação do empregado; h) treinamento do empregado; ei) inovação. Como salientam os autores a composição dos indicadores não financeiros varia de industria paraindústriae eão de difícil observação.

D e acordo com Copeland, Koller e Murrin (2000), 0 processo de definição de direcionadores de valor tem trêsfases: identificação, priorização einstitucionalização.

\section{A. Primeira Fase: Identificação}

A primeiratarefa écriar as árvores devalor que sistematicamente liguem os elementos operacionais do negócio à criação de valor. Enquanto as ligações matemáticas são desejadas, é melhor incluir uma ligação não quantificável do que omití-la. Também é recomendável desenharárvores em pelo menos trêsníveis paraprovocarcriatividade eamplitude. Nessa fase os gerentes podem integrar os direcionadores em uma simples árvore que melhor reflete o entendimento do negócio. Copeland, Koller e Murrin (2000) salientam que os gerentes de negócios devem estar diretamente envolvidos nos debatese nas definições desses direcionadores. Rappaport (1998) chama essa fase de definição dos mapas devalor;

\section{B. Segunda Fase: Priorização}

Uma vez que os gerentes já concordaram sobre uma árvore integrada, o próximo passo é determinar quais direcionadores de valor poderiam ter maior impacto no valor. A primeira parte da priorização é construir um modelo de fluxo de caixa descontado para testar a sensibilidade do valor da unidade de negócios para mudanças em cada um dos direcionadores de valor, verificando, um por um, qual o efeito que uma pequena mudança em cada direcionador de valor poderia gerar no fluxo de caixa. A segunda parteéanalisar um limitado número de direcionadores para determinar o potencial real ea facilidade de captação para cada ação de melhoria. 0 final dessa fase éa lista dos principais direcionadores de valor e o potencial associado a cada um delese

\section{Terceira Fase: Institucionalização}

Naúltima fase, os direcionadores de valor são incorporados nos objetivos e scorecards de performance de gerenciamento dos negócios. O s direcionadores de valor devem ser revisados periodicamente, dado que as alavancas de maior prioridade podem mudar, tais como as condições de mercado ou as habilidades e conhecimentos desenvolvidos pelacompanhia.

O balance scorecard é um mecanismo desenvolvido por Kaplan e Norton (1997) muito utilizado para identificar, mensurar e acompanhar os direcionadores fundamentais de valor de uma organização. 0 balanced scorecard é muito importante para transmitir a visão estratégica formulada pelos gestores da organização, bem como para 0 acompanhamento da aplicação dessa estratégia, pois evita que os gestores se concentrem apenas em alguns direcionadores de valor, tais como o fluxo de caixa, a estrutura de capital, o nível de crescimento dasvendas, o nível de inovação, esquecendo-se de outrosítens importantes como a satisfação do cliente ou o controle de qualidade do produto.

Todavia, o referencial teórico da gestão baseada em valores não contempla para cada direcionador uma fundamentação teórica capaz de explicar a natureza e a dinâmica de sua participação na geração de valor. Tanto a teoria microeconômica neoclássica que fundamenta a moderna teoria de finanças como esta que fundamenta a gestão baseada em valores, não apresentam igualmente uma justificativa teórica suficiente sobre função da tecnologia, exceto quanto mudança no preço dos fatores. Em vista disto, utiliza-se do modelo Estrutura-Conduta-Desempenho e Teoria dos Jogos.

\subsection{D irecionador Não Financeiro - Alta Tecnologia}

No modelo Estrutura-Conduta-D esempenho (ECD), segundo Bain (1966), a estrutura compreende: 1) o grau de concentração decompradores evendedores; 2) o grau de diferenciação do produto e 3) as condições de entrada e saída de um mercado. A conduta refere-se ao padrão de comportamento que as empresas obedecem para se ajustar as condições de mercado. A conduta compreende: 1) o mecanismo de fixação do preço ede determinação da produção:2) a políticapara os produtos ("portfólio" e "design", entre outros); 3) a política de propagandae publicidade $(\mathrm{P} \& \mathrm{P})$ e de pesquisa e desenvolvimento (P\&D) e 4) mecanismo de coordenação entre as políticas de preço, produção, propaganda e publicidade dos agentes em concorrência. 0 desempenho compreende: 1) os resultados da empresa como compradora dos fatores de produção; 2) os resultados da empresa como uma organização que administra seus recursos e 3 ) os resultados da empresa em relação ao meio-ambiente, ajustando-se as condições e exigências do mercado. 0 s equipamentos de alta tecnologia fazem parte da estrutura da indústria.

A estrutura determina a conduta, que por sua vez determina o desempenho da empresa e do mercado. Como exemplo, o grau de concentração dos vendedores (estrutura) determina o grau de colusão entre os mesmos (conduta) que por sua vez determina a lucratividade (desempenho). Existe, na formulação teórica original, portanto, um nexo causal entre estrutura, conduta e desempenho que é unilateral.

A diferenciação de produtos como dimensão da estrutura decorre das características dos produtos entre as indústrias ou na mesma indústria. A primeira resulta do próprio 
conceito de indústria entendida como um grupo de produtores que vendem bens substitutos próximos entre si. 0 grau de substituição dos produtos pode ser medido pela sua elasticidade preço da demanda. As causas mais evidentes da diferenciação são os diferentesatributos (extrínsicosou intrínsicos) ou características (simbólicas ou não) dos produtos ou serviços, a desinformação dos consumidores quanto aos elementos essenciais do produto e o poder de persuasão da propaganda e publicidade.

As barreiras à entrada funcionam com condicionantes fundamentais da formação de preço. As condições de entrada referem-seàs vantagens que os vendedores estabelecidos possuem sobre os possíveis entrantes, podendo aqueles praticar preçosindutivos ou preventivos, induzindo assim aentrada ou não denovos concorrentes. As empresas estabelecidas podem gozar da preferência dos consumidores pelos seus produtos, de modo que o entrante potencial teráderealizarum esforço adicional para deslocar parte da demanda para seus produtos. As barreiras à entrada podem, então, se referirem a atributos do produto, vantagens absolutas de custos eas economias de escala de produção e distribuição. Q uanto aos atributos, pode-se mencionar a preferência acumulada dos consumidores sobre influência da propaganda e publicidade, o "design" do produto e a acessibilidade ao mesmo, entre outros. Quanto às vantagens absolutas de custo pode-se mencionar as técnicas de produção superiores, tecnologia avançada de processo e produto, propriedadede patentes, acesso a fontes de crédito em condiçõesvantajosas, aquisição de fatores de produção a custos reduzidos. Q uanto às economias de escala de produção e distribuição, 0 entrante teria de possuir uma parcela de mercado equivalente para se beneficiar daquela ou então praticar uma promoção de vendas em grande escala para reduzir sua capacidade ociosa.

Entretanto, as vantagens absolutas de custos não aparecem como causa frequente e importante de barreiras à entrada. O s fatores determinantes da concentração são as economias das grandes plantas, das grandes firmas e daintegração vertical.

Sutton (1998) aponta algumas deficiências de natureza teórica do modelo ECD com relação à explicação de alguns comportamentos e se utiliza da Teoria dos Jogos para sua correção. A primeira refere-sea relação esentido da causalidade entre estrutura, conduta e desempenho, que pode ser bilateral. A segunda refere-se à natureza das barreiras à entrada, se endógena ou seexógena. D estemodo, gastos com propaganda e publicidade (P\&P), pesquisa e desenvolvimento (P\&D) ou equipamentos de alta tecnologia, que 0 autor denomina de "sunk costs" pode ser determinado internamente à indústria, como condição de equilíbrio, ou externamente à indústria, como elemento estratégico. Quando os "sunk costs" são endógenos, o número de empresas é menos sensível às variações do tamanho do mercado, ocorrendo o contrário, quando os custos são exógenos. A terceira refere-se àrelação entre P\&P e diferenciação de produto. Há empresas com produtos com elevado nível de diferenciação como, por exemplo, engenharia e saúde, e baixo nível de gastos com P\&P. A quarta refere-se à indústria com baixo nível de barreiras à entrada e concentração acima do esperado.

\section{METODOLOGIA}

O presente trabalho é resultado de uma pesquisa descritiva quantitativa, em que se aplicou o modelo de regressão linear múltipla a dados secundários, estimado por mínimos quadrados ordinários, utilizando-se o software "OxMetrics", baseando-se na metodologia de G apenski, Vogel e LanglandO rban (1993). Utilizou-se como banco de dados uma amostra de 1070 empresas da área de saúde com e sem fins lucrativos. O s dados foram obtidos junto a SERASA e as empresas do setor. Não fazem parte desse estudo as empresas públicas do setor de saúde, os serviços de Seguro Saúde e as empresas pertencentesao setor farmacêutico.

A exclusão dos serviços públicos desaúde se dá em função do objetivo de se obter resultados ligados ao desempenho econômico-financeiro das empresas hospitalares, resultados esses que não fazem parte dos objetivos primordiais das empresas públicas. Os Serviços de Seguro Saúde Privados foram excluídos, pois tais serviços são considerados clientes do setor de serviços de saúde, servindo como intermediários entre os prestadores de serviço (representado por hospitais, clínicas e laboratórios) e os clientes finais (representados pelos pacientes). Além disso, boa parte dos serviços de Seguro Saúde Privados estão ligados ainstituições financeiras que não participam do investimento em serviços de saúde. Esses aspectos poderiam distorcer significativamente os resultados, comprometendo os objetivos deste estudo. Já as empresas pertencentes ao setor farmacêutico não serão consideradas em virtude deserem, em sua maioria, empresas industriais, fornecedoras de produtos, tais como vacinas, remédios, etc, e não prestadoras de serviços de saúde, com formação e estrutura organizacional diferentes dos Hospitais, clínicas elaboratórios, equeinvestem em marketing, pesquisa e desenvolvimento.

Na medida em que a empresa tenha ações negociadas em bolsa de valores, suas ações terão uma cotação estabelecida pelo mercado, através das negociações de compra e venda à vista. E mbora se discuta até que ponto os preços definidos pelo mercado refletem com plena correção o valorintrínseco das ações, é inegável que tais preços são, em mercados desenvolvidos e mesmo em mercados emergentes, uma excelente base de avaliação do verdadeiro valor econômico das empresas e do seu capital próprio.

Empresas de capital fechado, embora possam estimar 0 seu possível valor de mercado, ficam sem a referência do próprio mercado para concluir se uma determinada metodologia deavaliação reflete efetivamente seu verdadeiro valor. D etoda forma, sejam empresas de capital fechado, sejam divisões de empresas de capital aberto, em qualquer caso é interessante, para fins de acompanhamento do desempenho da empresa ou até mesmo para fins de critérios de remuneração de execu- 
tivos, estabelecer uma metodologia de avaliação, levando em conta toda a tecnologia financeira hoje em dia disponível.

Algumas limitações merecem citação, como o fato deboa parte dos demonstrativos financeiros utilizados não terem sido auditados in locu por um órgão competente. A impossibilidade de se obterinformações mais detalhadas sobre os equipamentos, tais como marca, nacionalidade, tipo, ano, impediu melhor aprofundamento sobre o nível de atualização da tecnologia desse setor. D adaagrande quantidadedeempresas envolvidas na amostra desse estudo, não foi possível obter informações eexplicações sobrealguns dos dados estudados.

Considerando que somente uma empresa do setoré de capital aberto, optou-se por se utilizar como medidas de valor margens operacionais e retornos sobre os ativos, conforme se observa no quadro abaixo. Foram computados osvalores mé dios destes índices, considerando-se os anos de 2002 e 2003.

\section{ANÁLISE DOS RESULTADOS}

\section{Equipamentos em uso - Variável EquipUso}

A quantidade de equipamentos em uso representada pela variável EquipUso mostrou-se significante, porém com sinal contrário ao esperado, especialmente quanto ao retorno. Esses resultados não evidenciam, em parte, o potencial de contribuição dos equipamentos de alta tecnologia à rentabilidade. Além de seus exames serem boas fontes de receitas e de lucros, eles também exercem a função de facilitação e alavancagem de outros serviços, uma vez que o diagnóstico rápido do problema do paciente facilita a tomada de decisão do médico, bem como acelera a definição sobre a necessidade de uma cirurgia, internação, reencaminhamento, tratamento e outros serviços que empresa puder fornecer. Por outro lado, se aempresanão tiver esses equipamentos em volume suficiente, será obrigada a fazê-lo esperar, ou encaminhá-lo para umaoutra empresa prestar esse serviço ecorrero risco delenão fazer 0 exame e desistir do tratamento, ou ainda ser redirecionado à concorrência. Ambas as situações prejudicam o lucro da empresa. A construção destavariável como quantidade de equipamentos e não como valor médio pode ter comprometido sua representatividade. Entretanto, quanto se considera como variável dependente os resultados operacionais, esta variável mostrou-se significante, relevante e com sinal esperado, positivo.

A destinação dos equipamentos ao SUS - Variável PercEqui

Apesar do universo desseestudo estar concentrado em organizações privadas de saúde, algumas dessas empresas prestam serviços às organizações públicas, principalmente através do SUS, Sistema Único de Saúde. A variável PercE qui re-

Q uadro 2: Variáveis Independentes

Fonte: os autores 
presenta o percentual de equipamentos que as empresas pesquisadas disponibilizam para prestar serviços a esse órgão. Esta variável não possui significância estatística como variável explicativa do valor das empresas de saúde. Esses resultados não são condizentes com a diferença de remuneração que o SUS provêaos seus fornecedores em relação às Seguradoras de saúde e os planos de saúde. Como exemplo, pode-se citar a diferença de remuneração para um exame de Ressonância Magnética simples que 0 SUS paga cerca de R $\$ 263,00$, enquanto esse mesmo exame varia de $\mathrm{R} \$ 400,00 \mathrm{a}$ $\mathrm{R} \$ 800,00$ na iniciativa privada representada pelos pacientes diretos ou os Planos de Saúde.

\section{A Influência da D isponibilidade de leitos ao SUS - Variável SUS}

Apesar da baixa representatividade estatística da variável Size, os resultados da variável SUS foram estatisticamente significantes e mostraram relação negativa com relação às variáveis de lucratividade e retorno, indicando que a afiliação ao SUS compromete a lucratividade e o retorno da empresa. Esse resultado aponta para o fato de que a prestação de serviços ao SUS impacta negativamente a lucratividade e o retorno das organizações privadas de saúde pela baixa remuneração que o Sistema Único de Saúde pode oferecer a seus prestadores privados.

\section{O Nível de Endividamento - Variável Debt}

A variável D ebtfoi estatísticamente significante e teve uma relação negativa entre o nível de endividamento e os resultados da empresa. Esses números indicam que quanto maior o nível de endividamento da empresa, menor é sua lucratividade e 0 retorno. O s principais motivos desses resultados são as despesas financeiras geradas pela desvalorização cambial que ocorreu nos anos de 2002 e 2003 e pelos juros amortizados. Isso porque boa parte dessas dívidas é proveniente de aquisições de equipamentos importados. O s juros e a variação cambial do D ólar e do Euro afetaram negativamente a lucratividade das empresas, pois geralmente elas têm dificuldades de repassar essas despesas para seus preços em razão da prestação de serviços à saúde ser considerada item essencial eter o mercado regulado pelo G overno através da ANS - Agência Nacional de Saúde. O utro ponto importante é que as dívidas geralmente têm prazo de 3 a 7 anos e as empresas quase não se utilizam de estratégias financeiras de proteção, tais como "hedging" e derivativos, seja pelo desconhecimento, seja pelos altos custos dessa proteção em médio e longo prazo, que seria equivalente ao financiamento em Reais às taxas de juros brasileiras que são consideradas as mais altas do mundo.
Tabela 1 - Resultados de Regressão

\begin{tabular}{|c|c|c|c|c|}
\hline Variáveis & PTOM & АТОМ & PROA & $\Lambda \mathrm{RO \Lambda}$ \\
\hline EquipUso & $-0,0001$ & $-0,0003$ & $\begin{array}{c}-0,0065 \\
* *\end{array}$ & $\begin{array}{c}-0,0062 \\
* *\end{array}$ \\
\hline PercEqui & 0,0206 & 0,0133 & $-0,0281$ & $-0,0227$ \\
\hline Ensino & $-0,0248$ & $-0,0173$ & 0,0168 & 0,0068 \\
\hline Size & $-0,0000$ & $-0,0000$ & $-0,0000$ & $-0,0000$ \\
\hline SUS & 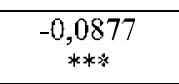 & $\begin{array}{c}-0,0865 \\
* * *\end{array}$ & $\underset{\substack{0,18 *\\
}}{-0,1882}$ & $\underset{\substack{* * * \\
\text { * }}}{-0,1753}$ \\
\hline Debt & $\begin{array}{c}-0,2230 \\
* * * *\end{array}$ & $\begin{array}{c}-0,2234 \\
* * * * *\end{array}$ & 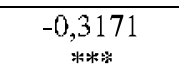 & $\underset{\substack{* * * * \\
\text { * }}}{-0,3123}$ \\
\hline Age & $\begin{array}{c}-0,0007 \\
* * * *\end{array}$ & $\begin{array}{c}-0,0006 \\
\approx *\end{array}$ & $\begin{array}{c}-0,0014 \\
* * *\end{array}$ & $\begin{array}{c}-0,0013 \\
*: *\end{array}$ \\
\hline Own & $\begin{array}{c}0,0594 \\
* * *\end{array}$ & $\begin{array}{c}0,0701 \\
* * *\end{array}$ & 0,0454 & 0,0227 \\
\hline DebitToE & 0,0002 & 0,0001 & 0,0003 & 0,0003 \\
\hline Imobiliz. & $-0,0000$ & $\begin{array}{c}-0,0000 \\
* *\end{array}$ & $-0,0000$ & $-0,0000$ \\
\hline QtyFilia & $-0,0001$ & $-0,0002$ & $-0,0054$ & $-0,0055$ \\
\hline Protesto & $-0,0000$ & $-0,0000$ & 0,0000 & 0,0000 \\
\hline $\begin{array}{l}\mathrm{R}^{2} \text {-Ajust } \\
\text { F-Stat } \\
\text { Reset }\end{array}$ & $\begin{array}{c}20,05^{\circ} \% \\
23,34 \\
(0,00001) \\
8,027(0,00)\end{array}$ & $\begin{array}{c}22,43 \% \\
26,76 \\
(0,00001) \\
8,703(0,00)\end{array}$ & $\begin{array}{c}12,56 \% \\
13,80 \\
(0,00001) \\
9,437(0,00)\end{array}$ & $\begin{array}{c}13,99 \% \\
15,49(0,00001) \\
7,876(0,00)\end{array}$ \\
\hline
\end{tabular}

\section{Fonte: os autores}

** significante a $5 \%$, *** significante a $1 \%$, *significante a menos de $10 \%$.

\section{Investimento em A tivo Fixo - A variável Imobiliz}

A variável Imobiliz, que representa o montante de ativo imobilizado da empresa, não apresentou resultados estatisticamente significantes, ainda que negativamente correlacionados às variáveis de retorno elucratividade. Esses resultados indicam que o volume maior de ativo imobilizado não necessariamente contribui para a lucratividade e retorno da empresa, pois, entre outros fatores, investimentos de alto custo, mas de pouca relação com a receita como instalações luxuosas, grandes construções e a existência de equipamentos 
que não estejam em uso podem representar altos custos fixos dedepreciação, limpeza, manutenção, conservação, seguro, etc que prejudiquem alucratividade da organização. Além disso, a logística interna de uma organização de saúde é muito importante para o bom aproveitamento da mão de obra e do fluxo de pacientes, e essa logística pode ficar prejudicada em instalações muito grandes e mal organizada. Um exemplo simples disso é ter o setor de Radiografias (Raios-X) muito longe do pronto socorro, pois demanda mais tempo de locomoção das pessoas e reduz a resolutividade da organização, atendendo menos pacientes e realizando menos procedimentos num dado período e, conseqüentemente, reduzindo alucratividade.

\section{A Idade da Empresa - Variável Age}

A idade da empresa representada pelavariável A ge mostrou-se significante, porém com sinal negativo. Isto indica que quanto mais antiga for a instituição, menor será o retorno e a lucratividade. Entretanto do ponto de vista financeiro este impacto é quase que desprezível.

\section{A Restrição de Crédito - Variável Protesto}

A quantidade de protestos não teve representatividade estatística, ainda que apresentando relação negativa com as variáveis de lucratividade e retorno. Normalmente os protestos causam restrição de crédito eprejudicam o poder debarganha das empresas com seus fornecedores, aumentando os custos e dificultando sua capacidade de diferenciação pela restrição de acesso à tecnologia e aos melhores profissionais. Além disso, essas empresas têm mais despesas financeiras, pois pagam juros mais altos pelo risco que representam, quando conseguem linhas de crédito. Todos esses fatores afetariam negativamente a lucratividade, principalmente nessa indústria em quea necessidade de capital de giro éalta, uma vez que as empresas têm um intervalo médio de recebimento de aproximadamente 60 dias, enquanto seus custos são pagos em médias de 30 a 45 dias, tais como folha de pagamento, honorários médicos, materiais consumíveis, entre outros.

A questão dos fins lucrativos ou não lucrativos - A variável Own

No Brasil ser uma empresa sem fins lucrativos não significa que seja proibida de ter lucro, mas sim de que não possa distribuir esses lucros, devendo ser reaplicados na própriainstituição. Além dessa obrigatoriedade, empresas brasileiras de saúde sem fins lucrativos têm que destinar cerca de $60 \%$ de seus serviços à iniciativa pública eà comunidade carente.

A Variável $\mathrm{O}$ wn diferencia se a empresa tem fins lucrativos (1) ou não tem fins lucrativos (0). O s resultados da regressão revelaram uma "curiosa" correlação negativa entre os fins lucrativos e as variáveis de lucratividade e retorno. Esse resultado écompreensível, pois as empresas com fins lucrati- vos são tributadas pelo fisco, enquanto as empresas sem fins lucrativos não têm nenhum tipo de tributação ou, no máximo, pagam impostos de forma reduzida. Além das empresas sem fins lucrativos terem vantagens fiscais que tornam o lucro líquido melhor, a maioria delas também pode adquirir equipamentos de alta tecnologia com custos mais baixos do que as empresas com fins lucrativos, pois são isentas de alguns impostos de importação, tais como IPI (Imposto sobre produtos industrializados), II (Imposto de Importação) e ICMS (Imposto sobreCirculação de Mercadoria eServiços). Isso faz com que tenham maior incentivo ao investimento em tecnologia e estejam melhor preparadas para atuarno mercado de Saúde. O s resultados dessa regressão são consistentes com o fato de que a empresa de melhor desempenho do mercado de saúde seja uma instituição sem fins lucrativos: 0 Hospital Albert Einsten.

\section{CONCLUSÃO}

O sprincipaisfatoresque contribuem paraalucratividade e 0 retorno das organizações privadas de saúde brasileiras estão relacionados à alocação de recursos em sua estrutura de operação, principalmenteno que diz respeito à tecnologia. A capacidade dos equipamentos de diagnósticos por imagem de gerar bons retornos foi o maior diferencial positivo entre os fatores pesquisados dessas empresas nos anos de $2002 \mathrm{e}$ 2003. As outras variáveis estruturais como quantidade de leitos, quantidade de filiais e tamanho não tiveram relevância estatística. A variável financeira - nível de endividamento mostrou-se com a mais impactante sobre o valor das empresas. 0 nível de endividamento, especialmente neste período após maxi-desvalorização, funcionou como um destruidor significativo de valor.

Talvez um estudo concentrado apenas em hospitais possa revelar maior significância estatística para a quantidade de leitos e também para realmente verificar se são positivamente correlacionados à lucratividade, pois alguns dos setores pesquisados não necessitam de leitos para realizarem seus serviços em abundância, como os centros de diagnósticos de imagens, os laboratórios, as clínicas e os consultórios.

Jáa representatividade de filiais pode ter sido comprometida pelo fato de algumas empresas, apesar de serem de um mesmo grupo de proprietários, terem razões sociais e CNPJ's diferentes. Um estudo baseado nos proprietários pode ser que dê mais subsídios para o entendimento das filiais ou interligações de hospitais em relação à lucratividade.

Também seevidenciou o impacto negativo àlucratividade que uma maior proporção de prestação de seus serviços ao SUS pode produzir, assim como a necessidade de maior ponderação em relação às decisões definanciamento que eles devem ter de forma a não terem seus lucros consumidos por despesas financeiras devido a umafalta de estratégia de proteção ou de umaboaanálise quanto aos custos de capital. 
Além disso, nesse estudo indica-se às instituições financeiras e aos bancos de fomento a possibilidade de reduzirem os preconceitos em relação às entidades privadas beneficentes sem fins lucrativos, pois o estudo mostrou que a correlação entre ser uma empresa com fins lucrativos énegativa em relação à lucratividade, levando a entender que as entidades sem fins lucrativos têm melhor lucratividade do que elas. Porém se faz necessário que outros estudos sejam feitos de forma a aprofundar o conhecimento acerca dos motivos pelos quais isso ocorre, abordando de forma mais detalhada a tributação, as eventuais receitas não operacionais advindas de doações, os tipos de serviços de filantropia que são fornecidos, bem como os serviços dedicados ao SUS.

Também pode ser de interessante para os órgãos governamentais verificarem o impacto de sua relação com as empresas privadas do setor de saúde, motivando-os a fazer um estudo mais pormenorizado e criar soluções para a melhor remuneração das empresas privadas, pois essas empresas podem chegar a um estado em que não terão mais condições de prestar serviços de boa qualidade ao SUS em função da incapacidadede reinvestimento quea baixa lucratividade gera. Por outro lado, é imprescindível ponderar que, de acordo com os dados da ANS, o SUS é responsável pela saúde de 137 milhões de brasileiros, representando cerca de $73 \%$ da população, e tem um orçamento bem restrito de cerca de $\mathrm{R} \$ 17,5$ bilhões para atender a essa demanda.

Esse estudo evidenciou a influência de alguns indicadores de valor para o acionista em relação ao desempenho financeiro das empresas privadas de saúde e também sucitou algumas frentes de estudo que podem ser feitas para o melhor entendimento desse setor no Brasil. Finalmente, cumpre salientar a necessidade de se utilizar outros procedimentos econométricos, tais como, panel data, em razão do objeto de estudo, não obstante a escassez de dados.

\section{REFERÊNCIAS BIBLIOGRÁFICAS}

BASSO , L. F. C.; KRAUTER, E.; KIMURA, H. The relationship between profit-sharing/ gain-sharing plans, productivity and economic value added. Journal of Academy of Business and Economics, 2004.

BAIN, J. Barriersto New Competition, Cambridge, MA: Harvard University Press, 1966.

BLACK, A.; WRIG HT , P.; D AVIE S, J. In Search of Shareholder Value: Managing the D rivers of Performance. Glasgow: Prentice Hall, 2001.

COPELAND, T.; KOLLEER, T.; MURRIN, J Valuation: Measuring And Managing TheV alue Of Companies. New York: John Wiley \& Sons, Inc, 2000.

GAPENSKI, L. C.; Vogel, W. B.; LANGLAND-ORBAN, B.. The Determinants of Hospital Profitability. Hospital and Health Services Administration, 38, 1, 1993.

HELFERT, E. A. Techniques of Financial Analyses: A guide to Value Creation. Irwin: McG raw-Hill. ed. 11, 2003.

ITTNER, C. D .; LARCKER, D . F.; RAJAN, M.V. The choice of performance measures in annual bonus contracts. TheAccounting Review, v. 72, n. 2., abril 1997.

KAPLAN, S. R.; NORTON, P. N. A Estratégia Em Ação: Balanced Scorecard. Rio de Janeiro: Elsevier, ed., 19, 1997.

Latin American Financial Studies - LAFIS. São Paulo,2004.

PETERSO N, P. P.; PETERSO N, D. R. PerformancedasEmpresas e Medidas de Valor Adicionado. Virginia: Fundação de Pesquisa do Instituto de Analistas Financeiros Certificados, 1996.

RAPPAPORT, A. Creating shareholder value. New Y ork: The Free Press, ed. 1, 1986.

Creating shareholder value: a guide for managers and investors. New Y ork: The Free Press, 1998.

REIMANN, B. C. Managing for Value. Oxford and London: Blackwell. In: ASSOCIATION WITH THE PLANNING FORUM, 1989.

STEWART, G. B. The Q uest for V alue. New York: Harper Business, 1991.

SUTTO N, J. Game Theory and Industry Studies. In: PHILIPS, L. In: Applied Industrial Organization. (org) Cap I. Cambridge Press. 1998.

YOUNG, D. S.; O’BYRNE, S. F. EVA e Gestão Baseada Em Valor. Porto Alegre: Bookman, 2003 